\title{
Angiographic factors associated with haemorrhagic presentation of brain arteriovenous malformation in a Chinese paediatric population
}

\author{
Elaine WS Fok *, WL Poon, KS Tse, HY Lau, CH Chan, NY Pan, HY Cho, TW Yeung, YC Wong, \\ KW Leung, Jennifer LS Khoo, KW Tang
}

\section{A B S T R A C T}

Objective: To identify specific angiographic factors associated with haemorrhagic presentation of brain arteriovenous malformation in Chinese paediatric patients.

Design: Retrospective cross-sectional observational study.

Setting: Four locoregional tertiary neurosurgical centres in Hong Kong: Queen Elizabeth Hospital, Tuen Mun Hospital, Kwong Wah Hospital, and Pamela Youde Nethersole Eastern Hospital.

Patients: Patients aged 18 years or younger who underwent pretreatment digital subtraction angiography for brain arteriovenous malformation between 1 January 2005 and 31 July 2013 were included. Patients were divided into haemorrhagic and non-haemorrhagic groups based on the initial presentation. Pretreatment digital subtraction angiographies were independently reviewed by two experienced neuroradiologists.

Main outcome measures: The following parameters were evaluated for their association with haemorrhagic presentation by univariate and multivariate analyses: nidus location, nidus size, nidus morphology (diffuse or compact); origin and number of arterial feeders; venous drainage; number of draining veins; presence of aneurysms, venous varices, and venous stenosis.

Results: A total of 67 children and adolescents (28 male, 39 female) with a mean age of 12 years were included. Of them, 52 (78\%) presented with haemorrhage. Arteriovenous malformation size $(\mathrm{P}=0.004)$ and morphology $(\mathrm{P}=0.05)$ were found to be associated with haemorrhagic presentation by univariate analysis. Small arteriovenous malformation nidus size and diffuse nidal morphology were identified as independent risk factors for haemorrhage by multivariate analysis.

Conclusion: Smaller arteriovenous malformation size and diffuse nidal morphology are angiographic factors independently associated with haemorrhagic presentation. Bleeding risk is important in determining the therapeutic approach (aggressive vs conservative) and timeframe, particularly in paediatric patients.

\section{Hong Kong Med J 2015;21:401-6 \\ DOI: 10.12809/hkmj144339}

1 EWS Fok *, FRCR, FHKCR

${ }^{1}$ WL Poon, FRCR, FHKAM (Radiology)

KS Tse, FRCR, FHKAM (Radiology)

${ }^{1}$ HY Lau, FRCR, FHKAM (Radiology)

${ }^{2} \mathrm{CH}$ Chan, MB, BS, FRCR

${ }^{2}$ NY Pan \#, FRCR, FHKAM (Radiology)

${ }^{2}$ HY Cho, FRCR, FHKAM (Radiology)

${ }^{3}$ TW Yeung, FRCR, FHKCR

${ }^{3}$ YC Wong, FRCR, FHKAM (Radiology)

${ }^{4}$ KW Leung, FRCR, FHKAM (Radiology)

${ }^{4}$ JLS Khoo, FRCR, FHKAM (Radiology)

${ }^{1} \mathrm{KW}$ Tang, FRCR, FHKAM (Radiology)

${ }^{1}$ Department of Radiology and Imaging, Queen Elizabeth Hospital, Jordan, Hong Kong

${ }^{2}$ Department of Radiology, Kwong Wah Hospital, Yaumatei, Hong Kong

${ }^{3}$ Department of Radiology and Nuclear Medicine, Tuen Mun Hospital,

Tuen Mun, Hong Kong

${ }^{4}$ Department of Radiology, Pamela Youde Nethersole Eastern Hospital, Chai Wan, Hong Kong

* Corresponding author: elainefokws@gmail.com

\# Currently at Department of Radiology, Princess Margaret Hospital, Laichikok, Hong Kong

New knowledge added by this study

- Studies on paediatric arteriovenous malformation (AVM) are scarce and mostly based in Caucasian populations. This multicentre study involving Chinese paediatric patients found that small AVM nidus size and diffuse nidal morphology are independent risk factors for haemorrhage.

Implications for clinical practice or policy

- These two angiographic features associated with haemorrhagic presentation can help local clinicians to assess bleeding risk and determine the therapeutic approach (aggressive vs conservative) and treatment timeframe in paediatric patients with cerebral AVM. 


\section{華籍兒童腦動靜脈畸形與出血相關的 血管造影因素}

霍泳珊、潘偉麟、謝健楸、劉顯宇、陳志軒、潘寧遠、

曹慶恩、楊子慧、王耀忠、梁錦榮、邱麗珊、鄧國穎

目的：找出與腦動靜脈畸形華籍兒童患者出血相關的血管造影因素。

設計：回顧性橫斷面觀察研究。

安排：香港提供第三層醫療服務的四間腦外科中心：伊利沙伯醫院 屯門醫院、廣華醫院和東區尤德夫人那打素醫院。

患者：2005年1月 1 日至2013年7月31日期間因腦動靜脈畸形進行術前 數字減影血管造影的 18 歲或以下患者均被列入研究範圍。根據患者病 發時的情況把他們分為出血性和非出血性兩組, 並由兩位經驗豐富的 神經放射學醫生分別進行獨立審閲術前數字減影血管造影的影像。

主要結果測量：通過單變量和多變量分析為以下各項與出血相關的因 素進行評估：病灶位置、大小和形態（濔漫性或致密型）、供血動脈 的來源和數量、引流靜脈的目的地和數量, 以及是否出現動脈瘤、靜 脈曲張和靜脈狹窄。

結果：共67名兒童及青少年（28男39女；平均年齡 12 歲）被列入研究 範圍, 其中 52 人 $(78 \%)$ 病發時有出血。單變量分析顯示腦動靜脈畸 形的大小 $(\mathrm{P}=0.004)$ 和形態 $(\mathrm{P}=0.05)$ 與出血有關。多變量分析則 顯示小型腦動靜脈畸形和其擴散形態為出血的獨立危險因素

結論：小型腦動靜脈畸形和擴散形態均為血管造影中與出血相關的獨 立因素。採用積極或保守的治療方法以及治療時間表均取決於患者的 出血風險, 尤以兒童患者為甚。

\section{Introduction}

Brain arteriovenous malformation (AVM) is a vascular abnormality that consists of multiple fistulous connections between arteries and veins without a normal intervening capillary bed. It is believed to be congenital in nature, and commonly presents in early adulthood. ${ }^{1}$ The usual clinical presentations of brain AVM include haemorrhage, seizures, headache, and progressive neurological deficit. About $52 \%$ to $77 \%$ of patients with AVM have initial haemorrhagic presentation, ${ }^{2-4}$ which is also associated with poorer prognosis. Various studies evaluating the history of AVM record an annual haemorrhage rate of about $2 \%$ to $4 \%{ }^{1,5}$

Computed tomography (CT) is the initial screening tool for identifying haemorrhage and demonstrating the location of the AVM. Subsequent angiographic evaluation is required for virtually all patients with suspected AVM, with digital subtraction angiography (DSA) being accepted as the gold standard for characterisation and grading. The information obtained from the angiogram is crucial in treatment decision-making and prognostication.

Brain AVM is an important cause of haemorrhagic stroke in children. ${ }^{6-8}$ Studies in adults have identified radiological features that are associated with haemorrhagic presentation and future haemorrhage. ${ }^{9-11}$ Similar studies on AVM in children are, however, scarce and mostly based on studies from Europe and North America. ${ }^{12,13}$ Whether those angiographic features that predict haemorrhage in Caucasian children with AVM similarly predict haemorrhage in Chinese children with AVM is unknown.

The objective of this multicentre study was to determine specific angiographic factors associated with haemorrhagic presentation in brain AVM in the Hong Kong Chinese paediatric population, with a view to assisting clinical decision-making regarding the optimal timing and type of treatment.

\section{Methods}

This was a multicentre retrospective cross-sectional observational study. We included patients aged 18 years or younger (at time of diagnosis) who underwent pretreatment cerebral DSA for a principal diagnosis of brain AVM from 1 January 2005 to 31 July 2013.

Patients were recruited from four locoregional tertiary neurosurgical centres in Hong Kong: Queen Elizabeth Hospital, Tuen Mun Hospital, Kwong Wah Hospital, and Pamela Youde Nethersole Eastern Hospital. These are the major acute hospitals belonging to the catchment areas of Kowloon Central, New Territories West, Kowloon West, and Hong Kong East clusters, respectively, according to the geographical cluster designation by the Hospital Authority. These clusters serve approximately 4 million Hong Kong inhabitants. Consecutive patients were retrieved from the Clinical Data Analysis and Reporting System by entering the targeted date range (01 January 2005 to 31 July 2013, inclusive) and the following search parameters: age range (0-18 years); International Classification of Diseases, 9th Revision, diagnostic code (747.81, AVM); and procedure code (88.41, arteriography of cerebral arteries). Exclusion criteria included a lack of accessible pretreatment DSA, other angiographic diagnoses (eg spinal AVM, vein of Galen aneurysmal malformation, dural arteriovenous fistulae), and non-Chinese ethnicity based on data extracted from the electronic Patient Record (ePR) and radiology reports. Approval was obtained from the institutional ethics committee and patient consent was waived for this retrospective study.

Basic demographic factors, including age at presentation and clinical symptoms, were obtained from the ePR. Patients were divided into a haemorrhagic group (those presenting with intracranial haemorrhage) and a non-haemorrhagic group based on the $\mathrm{CT}$ of the brain at presentation. Pretreatment DSAs were independently reviewed by two experienced interventional neuroradiologists (with 7 years and 15 years of experience) who were blinded to the clinical presentation and provided with the same demographic data. Each brain AVM 
was evaluated for the following parameters: nidus location (deep: thalamus, basal ganglia, corpus callosum, or brain stem vs hemispheric: cerebral or cerebellar lobes), nidus size (small $<3 \mathrm{~cm}$ vs medium $3-6 \mathrm{~cm}$ vs large $>6 \mathrm{~cm}$ ), nidus morphology (compact: little or no intervening brain within the nidus vs diffuse: presence of significant intervening brain within the nidus) [Figs 1 and 2], origin of arterial feeders (cortical vs deep), number of arterial feeders (single vs multiple), presence of either flow-related or intranidal aneurysms (yes vs no), venous drainage destination (superficial vs deep), number of draining veins (single vs multiple), presence of venous varices (yes vs no), and presence of venous stenosis (yes vs no). Any discrepancy in reviews between the two neuroradiologists was resolved by mutual consensus.

Association between the angiographic features and haemorrhage was analysed using Chi squared test and Fisher's exact test for categorical variables, and Student's $t$ test for numerical variables in univariate analysis. Logistic regression (with "enter" strategy) was carried out for covariates with a P value of $<0.15$. All statistical calculations were performed using the Statistical Package for the Social Sciences (Windows version 16.0; SPSS Inc, Chicago [IL], US).

\section{Results}

The sample included 67 children and adolescents who were eligible for inclusion, of which 28 (42\%) were boys and 39 (58\%) were girls. Among the patients, 52 (78\%) were in the haemorrhagic group and 15 (22\%) were in the non-haemorrhagic group. The mean age at presentation was 12 years (range, $2-18$ years $)$. No significant differences in age $(\mathrm{P}=0.15)$

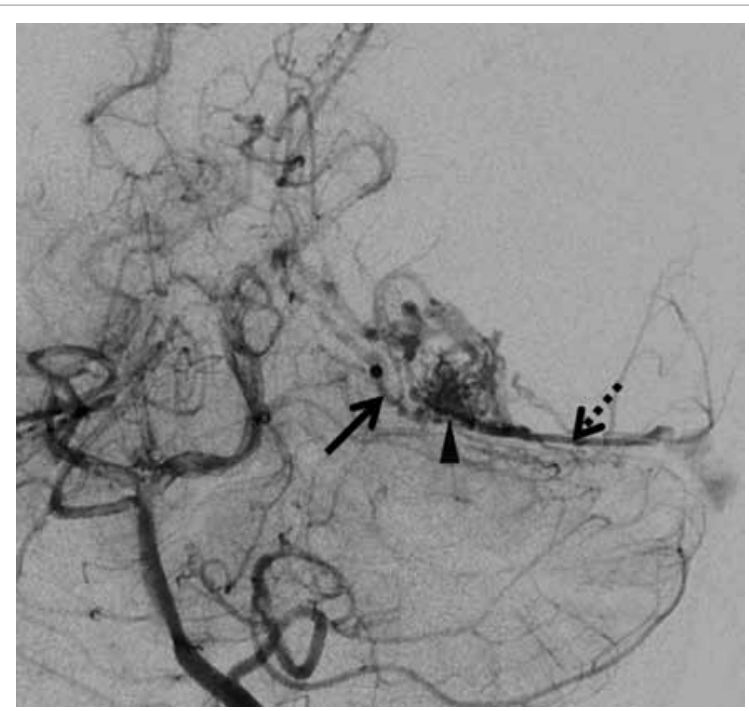

FIG I. Left occipital arteriovenous malformation, supplied solely by the posterior circulation via branches of the left posterior cerebral artery (solid arrow) and with deep venous drainage into the sigmoid sinus (dashed arrow)

The nidus (arrowhead) is compact (nodular or mass-like) and small, measuring $1.5 \mathrm{~cm}$
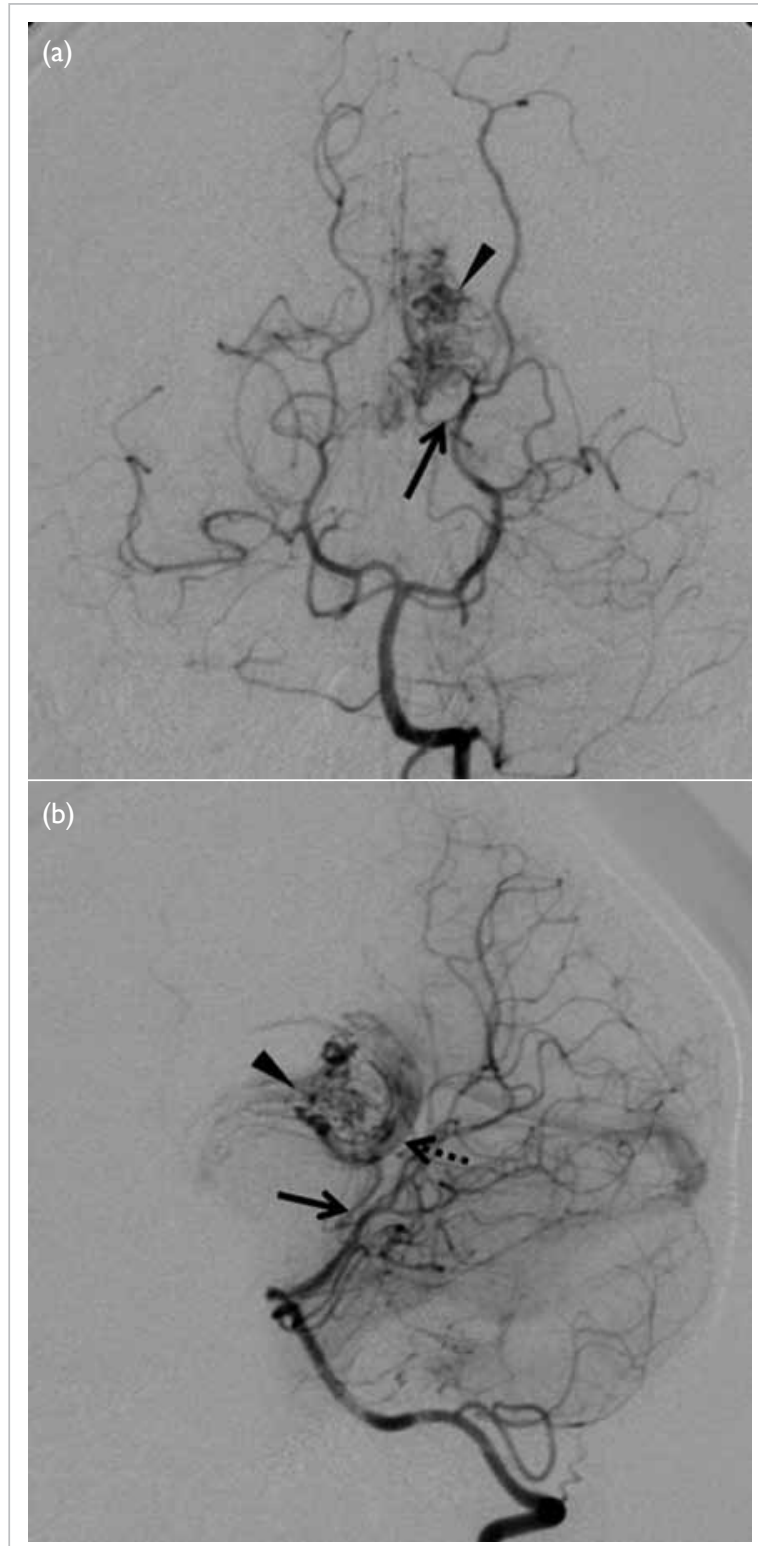

FIG 2. (a) Anterior and (b) lateral views of an arteriovenous malformation in the splenium of the corpus callosum, with arterial supply from the splenial branch of the left posterior cerebral artery (solid arrows) and deep venous drainage into the great vein of Galen (dashed arrow). The nidus (arrowheads) is small (measuring $<3 \mathrm{~cm}$ ) and diffuse in morphology

or sex $(\mathrm{P}=0.88)$ were demonstrated between the haemorrhagic and non-haemorrhagic groups. Of the 67 patients, one in the haemorrhagic group was known to have idiopathic thrombocytopenic purpura. The remaining 66 patients had no known medical condition predisposing to intracranial haemorrhage.

Of the 67 children, 25 (37\%) presented with headache, $12(18 \%)$ with hemiplegia, 11 (16\%) with convulsion, seven (10\%) with collapse, three (4\%) with loss of consciousness, one (1\%) with cerebellar signs, and eight (12\%) had other features, including confusion, decreased responsiveness, numbness, 
and restricted ocular motion. There were more asymptomatic patients in the non-haemorrhagic group (Fig 3). Three patients, all of whom were in the non-haemorrhagic group, were diagnosed incidentally with AVM during examination for precocious puberty, scalp haemangioma, and suspected neurofibromatosis type 1 .

The frequency of haemorrhage of the 67 patients as a function of angioarchitectural features is shown in Table 1.

After univariate analysis, AVM size $(\mathrm{P}=0.004)$ and morphology $(\mathrm{P}=0.05)$ were the two factors found to be significantly associated with haemorrhagic presentation (Table 2). After multivariate analysis, small AVM size and diffuse nidal morphology were identified as independent riskfactors for haemorrhage (Table 3). The odds of haemorrhagic presentation in patients with small AVM was about 9 times that of patients with medium-size AVM, whereas the odds for haemorrhagic presentation in patients with diffuse nidal morphology was approximately 12 times that of patients with compact AVM morphology. Factors found not to be statistically significantly associated with haemorrhagic presentation included location, origin of arterial feeders, number of arterial feeders, presence of related aneurysms, venous drainage, number of draining veins, presence of venous varices, and presence of venous stenosis.

\section{Discussion}

To date, DSA remains the gold standard for evaluating brain AVM owing to its superior temporal and spatial resolution, with the ability to provide dynamic information and allow accurate identification of supplying arteries and draining veins. Generally CT and magnetic resonance angiography studies do not provide important dynamic information on the arterial supply and venous drainage.

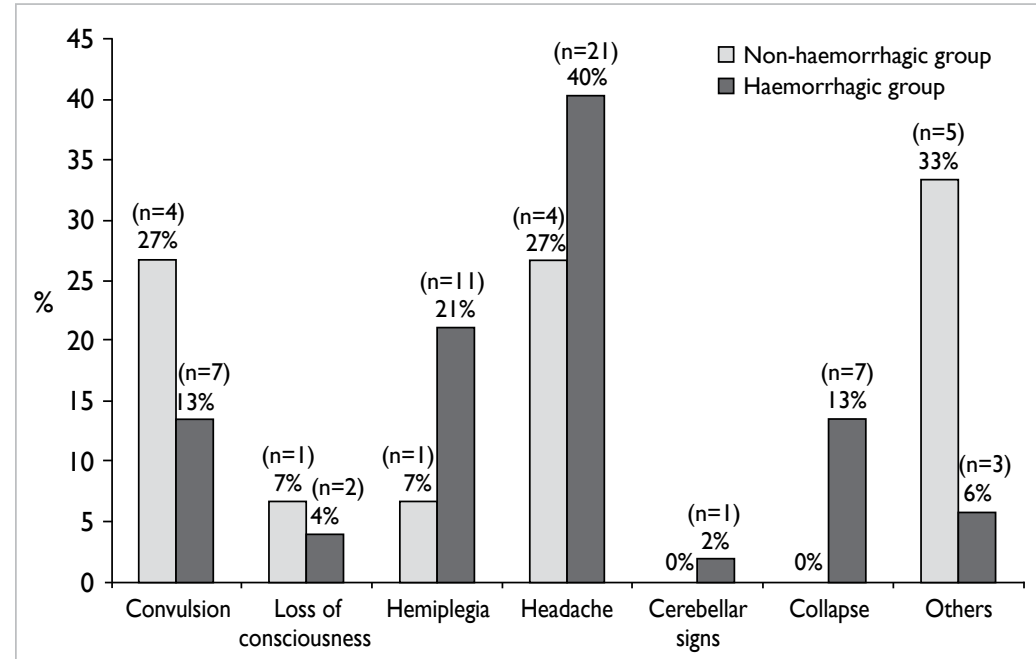

FIG 3. Presenting symptoms in the haemorrhagic and non-haemorrhagic groups
Current treatment approaches for brain AVM include microsurgical resection, stereotactic radiosurgery, embolisation, a combination of these methods, and watchful waiting. As each patient with AVM is different, there is no universal algorithm or protocol to be followed. The management of brain AVM is highly individualised, requiring careful consideration of multiple factors, including lesionrelated factors (eg size, location, and configuration) which can be obtained from cerebral angiogram; patient-related factors (eg life expectancy, general health, and lifestyle); and treatment-related risks. Children with AVM pose a particular problem in that they have a high cumulative bleeding risk due to their young age at presentation, and any insult to the developing brain (either spontaneous haemorrhage

TABLE I. Frequency of haemorrhage as a function of angioarchitectural features in paediatric brain arteriovenous malformation $(n=67)$

\begin{tabular}{|c|c|c|}
\hline Feature & Total No. & $\begin{array}{l}\text { No. }(\%) \text { of patients } \\
\text { with haemorrhage }\end{array}$ \\
\hline \multicolumn{3}{|l|}{ Location } \\
\hline Deep & 22 & $19(86.4)$ \\
\hline Hemispheric & 45 & 33 (73.3) \\
\hline \multicolumn{3}{|l|}{ Size } \\
\hline$<3 \mathrm{~cm}$ & 45 & $40(88.9)$ \\
\hline $3-6 \mathrm{~cm}$ & 22 & $12(54.5)$ \\
\hline \multicolumn{3}{|l|}{ Morphology } \\
\hline Compact & 48 & $34(70.8)$ \\
\hline Diffuse & 19 & $18(94.7)$ \\
\hline \multicolumn{3}{|l|}{ Venous drainage } \\
\hline Superficial & 40 & $29(72.5)$ \\
\hline Deep & 27 & 23 (85.2) \\
\hline \multicolumn{3}{|l|}{ Draining vein } \\
\hline Single & 39 & 32 (82.1) \\
\hline Multiple & 28 & $20(71.4)$ \\
\hline \multicolumn{3}{|c|}{ Intranidal aneurysm } \\
\hline Present & 18 & $13(72.2)$ \\
\hline Absent & 49 & 39 (79.6) \\
\hline \multicolumn{3}{|l|}{ Venous varix } \\
\hline Present & 6 & $3(50.0)$ \\
\hline Absent & 61 & $49(80.3)$ \\
\hline \multicolumn{3}{|l|}{ Venous stenosis } \\
\hline Present & 4 & $2(50.0)$ \\
\hline Absent & 63 & $50(79.4)$ \\
\hline \multicolumn{3}{|l|}{ Feeding artery } \\
\hline Single & 15 & $13(86.7)$ \\
\hline Multiple & 52 & $39(75.0)$ \\
\hline \multicolumn{3}{|c|}{ Origin of feeding artery } \\
\hline Cortical & 49 & $37(75.5)$ \\
\hline Deep & 18 & 15 (83.3) \\
\hline
\end{tabular}


TABLE 2. Univariate analysis of the angiographic features associated with haemorrhagic presentation

\begin{tabular}{|c|c|}
\hline Clinical/radiological factor & $P$ value \\
\hline Location (hemispheric vs deep) & $0.351^{*}$ \\
\hline Size (small <3 cm vs medium $3-6 \mathrm{~cm}$ ) & $0.004 \dagger$ \\
\hline Morphology (diffuse vs compact) & $0.050^{*}$ \\
\hline Venous drainage destination (deep vs superficial) & $0.222 \dagger$ \\
\hline No. of draining veins (1 vs >1) & $0.306 \dagger$ \\
\hline Related aneurysm (no vs yes) & $0.524^{*}$ \\
\hline Varix (no vs yes) & $0.121^{\star}$ \\
\hline Venous stenosis (no vs yes) & $0.214^{*}$ \\
\hline No. of feeding arteries ( 1 vs $>1$ ) & $0.490^{*}$ \\
\hline Origin of feeding artery (deep vs superficial) & $0.742^{*}$ \\
\hline
\end{tabular}

or treatment-related morbidity) may have lifelong and profound sequelae. ${ }^{14}$

To the best of our knowledge, our study is the first to evaluate the risk factors for brain AVM haemorrhage in Chinese paediatric patients. Ethnic differences exist in the incidence and haemorrhagic risk of AVM, and data from western populations are not routinely generalisable to the Chinese population. A cohort study of 1028 adult patients with AVM in the US has established a role of ethnic differences in brain AVM, with excess incidence in Asians, blacks, and Hispanics compared with Caucasians. ${ }^{15}$ The analysis reveals a statistically significant increased risk for subsequent AVM haemorrhage among Hispanics compared with Caucasians, and an insignificant trend for blacks and Asians.

Studies in adults have identified specific angiographic features of AVM that are associated with haemorrhagic presentation and future bleeding, including small size $(<3 \mathrm{~cm})$, deep location, deep venous drainage, single draining vein, intranidal aneurysms, and associated venous ectasia or stenosis. $^{5,14,16,17}$

Our study identified small AVM size $(<3 \mathrm{~cm})$ to be an independent risk factor for haemorrhage. Small AVM size has been identified as a risk factor for haemorrhage in multiple adult studies, ${ }^{5,18-20}$ which is also demonstrated in a western paediatric population. ${ }^{12}$ Although the underlying pathophysiological mechanism is uncertain, some authors have postulated a relationship between AVM size and feeding artery pressures. ${ }^{8,12}$ Spetzler et $\mathrm{al}^{17}$ found a higher rate of haemorrhagic presentation among smaller AVMs and noted that smaller AVMs were associated with higher feeding artery pressures at the time of surgical management as well as larger haematoma sizes.

Diffuse AVM nidal morphology was identified as another independent risk factor for haemorrhage in our study. Although a similar relationship between morphology and haemorrhage was not demonstrated in a Caucasian paediatric population, ${ }^{12}$ diffuse AVM nidal morphology has been demonstrated in adults as a risk factor for haemorrhage. ${ }^{21}$ The underlying pathophysiological mechanism is uncertain. More information is needed to determine whether diffuse morphology is associated with haemodynamic aberrations such as increased pressure in the feeding artery or draining vein to account for the observed increased risk of haemorrhage.

Our study has several limitations. First, owing to the retrospective nature of this study, AVM patients with poorer clinical presentation who are unfit for DSA were not included. Second, although this is a multicentre study, the sample size was relatively small owing to the small number of paediatric patients undergoing DSA for AVM. Our study has also underestimated the haemorrhagic proportion of the study population, thus any potential associations between other angiographic features with haemorrhagic presentation that are more subtle to detect would remain undetected. Third, variations exist in the quality and amount of available angiographic images, as well as in the level of experience of the angiographers among the various centres; these may affect the radiological interpretation. Presence of intracranial haemorrhage can be inferred from the pretreatment DSA due to presence of blood vessel displacement, which is an inherent limitation of this study. Fourth, as presence of haemorrhage may render an originally compact nidus into a diffuse morphology, this is a limiting factor in determining the association between diffuse morphology and haemorrhagic presentation. Fifth, we were unable to control for the timing of DSA following the onset of presentation owing to the retrospective nature of this study. Lastly, the extent to which certain angiographic risk factors existent at the time of haemorrhagic presentation can be extrapolated as predictors of future haemorrhage in AVM is controversial. In other words, factors present at the time of presentation are not necessarily accurate predictors of future risk. For instance, several adult-based studies have identified a higher incidence of haemorrhagic presentation in small

TABLE 3. Multivariate analysis of the angiographic features associated with haemorrhagic presentation

\begin{tabular}{lcccc}
\hline Feature & B value & Exp & P value & 95\% Confidence interval \\
\hline Size (small vs medium) & 2.22 & 9.186 & 0.002 & $2.33-36.12$ \\
Morphology (diffuse vs compact) & 2.46 & 11.74 & 0.031 & $1.26-109.76$ \\
\hline
\end{tabular}


AVMs, but failed to find an association between AVM size and future haemorrhage. .2,23 $^{2}$

Unlike in adults, large-scale prospective studies aiming to study the natural course of paediatric AVMs are unlikely to take place owing to the relatively strong argument against conservative treatment, according to the prevailing view that ruptured paediatric AVMs should be treated aggressively owing to the significant risk of recurrent haemorrhage and subsequent morbidity and mortality. ${ }^{12,24}$ The recent controversial ARUBA (A Randomised trial of Unruptured Brain Arteriovenous malformations) in adults has demonstrated that medical management alone is superior in patients with unruptured AVMs, ${ }^{25}$ but there is insufficient scientific evidence to justify extrapolation of these results to a paediatric population. Moreover, while it has been shown that paediatric AVMs with haemorrhagic presentation do not necessarily have a higher risk of future haemorrhage nor a higher annualised bleeding risk than adults, ${ }^{26}$ their greater cumulative risk given their longer remaining life expectancy may be an argument for more aggressive treatment of paediatric AVMs. Choice of treatment for a small, unruptured paediatric AVM is therefore complex and should involve thorough consideration of other angioarchitectural factors on a case-by-case basis.

Despite these limitations, our study provides useful initial insights to the angiographic features associated with haemorrhagic presentation of AVMs in Chinese paediatric patients from multiple locoregional neurosurgical centres. These features may assist in stratifying risk of haemorrhage and assign priority for intervention, although data from future larger-scale studies may be needed before such features can be robustly applied as haemorrhagic risk predictors in Chinese children with AVM.

\section{References}

1. Ondra SL, Troupp H, George ED, Schwab K. The natural history of symptomatic arteriovenous malformations of the brain: a 24-year follow-up assessment. J Neurosurg 1990;73:387-91.

2. Choi JH, Mohr JP. Brain arteriovenous malformations in adults. Lancet Neurol 2005;4:299-308.

3. Freidlander RM. Clinical practice. Arteriovenous malformations of the brain. N Engl J Med 2007;356:2704-12.

4. Hofmeister C, Stapf C, Hartmann A, et al. Demographic, morphological, and clinical characteristics of 1289 patients with brain arteriovenous malformation. Stroke 2000;31:1307-10.

5. Graf CJ, Perret GE, Torner JC. Bleeding from cerebral arteriovenous malformations as part of their clinical history. J Neurosurg 1983;58:331-7.

6. Jordan LC, Hillis AE. Hemorrhagic stroke in children. Pediatr Neurol 2007;36:73-80.

7. Meyer-Heim AD, Boltshauser E. Spontaneous intracranial haemorrhage in children: aetiology, presentation and outcome. Brain Dev 2003;25:416-21.

8. Giroud M, Lemesle M, Madinier G, Manceau E, Osseby
GV, Dumas R. Stroke in children under 16 years of age. Clinical and etiological difference with adults. Acta Neurol Scand 1997;96:401-6.

9. Stefani MA, Porter PJ, terBrugge KG, Montanera W, Willinsky RA, Wallace MC. Angioarchitectural factors present in brain arteriovenous malformations associated with hemorrhagic presentation. Stroke 2002;33:920-4.

10. Turjman F, Massoud TF, Viñuela F, Sayre JW, Guglielmi G, Duckwiler G. Correlation of the angioarchitectural features of cerebral arteriovenous malformations with clinical presentation of hemorrhage. Neurosurgery 1995;37:85660; discussion 860-2.

11. Nataf F, Meder JF, Roux FX, et al. Angioarchitecture associated with haemorrhage in cerebral arteriovenous malformations: a prognostic statistical model. Neuroradiology 1997;39:52-8.

12. Ellis MJ, Armstrong D, Vachhrajani S, et al. Angioarchitectural features associated with hemorrhagic presentation in pediatric cerebral arteriovenous malformations. J Neurointerv Surg 2013;5:191-5.

13. Di Rocco C, Tamburrini G, Rollo M. Cerebral arteriovenous malformations in children. Acta Neurochir (Wien) 2000;142:145-56; discussion 156-8.

14. Fleetwood IG, Steinberg GK. Arteriovenous malformations. Lancet 2002;359:863-73.

15. Kim H, Stephen S, McChulloch, et al. Racial/ethnic differences in longitudinal risk of intracranial hemorrhage in brain arteriovenous malformation patients. Stroke 2007;38:2430-7.

16. Farhat HI. Cerebral arteriovenous malformations. Dis Mon 2011;57:625-37.

17. Spetzler RF, Hargraves RW, McCormick PW, Zabramski JM, Flom RA, Zimmerman RS. Relationship of perfusion pressure and size to risk of hemorrhage from arteriovenous malformations. J Neurosurg 1992;76:918-23.

18. Crawford PM, West CR, Chadwick DW, Shaw MD. Arteriovenous malformations of the brain: natural history in unoperated patients. J Neurol Neurosurg Psychiatry 1986;49:1-10.

19. Guidetti B, Delitala A. Intracranial arteriovenous malformations. Conservative and surgical treatment. J Neurosurg 1980;53:149-52.

20. Itoyama Y, Uemura S, Ushio Y, et al. Natural course of unoperated intracranial arteriovenous malformations: study of 50 cases. J Neurosurg 1989;71:805-9.

21. Pollock BE, Flickinger JC, Lunsford LD, Bissonette DJ, Kondziolka D. Factors that predict the bleeding risk of cerebral arteriovenous malformations. Stroke 1996;27:1-6.

22. da Costa L, Wallace MC, Ter Brugge KG, O'Kelly C, Willinsky RA, Tymianski M. The natural history and predictive features of hemorrhage from brain arteriovenous malformations. Stroke 2009;40:100-5.

23. Stapf C, Mast H, Sciacca RR, et al. Predictors of hemorrhage in patients with untreated brain arteriovenous malformation. Neurology 2006;66:1350-5.

24. Blauwblomme T, Bourgeois M, Meyer P, et al. Long-term outcome of 106 consecutive pediatric ruptured brain arteriovenous malformations after combined treatment. Stroke 2014;45:1664-71.

25. Mohr JP, Parides MK, Stapf C, et al. Medical management with or without interventional therapy for unruptured brain arteriovenous malformations (ARUBA): a multicentre, non-blinded, randomised trial. Lancet 2014;383:614-21.

26. Fullerton HJ, Achrol AS, Johnston SC, et al. Long-term hemorrhage risk in children versus adults with brain arteriovenous malformations. Stroke 2005;36:2099-104. 